\title{
Geomechanical Substantiation of the Parameters of Injection Fixing of the Soil Bases During the Liquidation of the Emergency Condition of the Structure
}

\author{
Mikhail Sokolov ${ }^{1}$, Sergey Prostov ${ }^{1, *}$, and Igor Kharitonov ${ }^{2}$ \\ ${ }^{1}$ T.F. Gorbachev Kuzbass State Technical University, 650000 Vesennyaya st. 28, Kemerovo, Russia \\ ${ }^{2}$ OJSC «SUEK-Kuzbass», 652507 Vasilyeva street 1, Leninsk-Kuznetsky, Russia
}

\begin{abstract}
The emergency condition of a structure that is complex in plan of and located in the mine development zone. As a result of a complex of engineering-geological and geophysical surveys it was established that the cause of significant deformations of the foundations of the structure are the zones of weakened and water-saturated grounds at the base of the foundations, formed due to changes in the hydrogeological regime and man-made accidents. The technique of substantiation of technological parameters of the injection method to soil consolidation is described, including computer modeling, forecasting of deformations of the natural and fixing massif, analysis of the stress-strain state of soils in the most dangerous area. The effectiveness of the adopted scheme of injecting reinforcement was confirmed according to the approved methodology for liquidation of an emergency condition of a mining structure. It is proposed to create additional fixed zones within the formed zone.
\end{abstract}

\section{Introduction}

In order to effectively apply methods for managing the state and properties of unstable soil masses, modern techniques for determining technological parameters at the design stage are needed, which are based on the results of studies of zones with low building properties, on monitoring changes in these properties during and after processing [1-4]. Such studies are based on geological and geophysical monitoring methods, which are divided into visual and instrumental, including complexes of mechanical, hydro-, gas-dynamic and geophysical methods. Forecasting of a steady state of objects is made by results of geocontrol with the use of empirical, analytical and numerical methods of processing, including specialized nomograms, algorithms and computer programs [5].

At the present time, the methods of geomechanical modeling are developing very intensively, the main advantage of which is the possibility of establishing fundamental regularities in the change of the geomechanical state of soil bases in a wide range of geological and mining-technical conditions. Analytical methods of calculation are based on

\footnotetext{
${ }^{*}$ Corresponding author: psm.tigm@kuzstu.ru
} 
the classical laws of geomechanics and give acceptable accuracy of the solution only for homogeneous arrays and simple of calculation schemes [6,7]. Methods of numerical computer simulation are increasingly being used to solve geomechanical problems [8-10]. The most widely used is the finite element method, the main theoretical and methodological positions of which are presented in fundamental monographs, and practical results are given in [11-13].

\section{Research Methodology}

A complex methodology has been developed, the essence of which is to integrate the geomechanical forecast into the existing method of geotechnical blocks developed at the "UralPromStroyNIIProekt" research Institute and the Institute of Geology and Geochemistry. The algorithm of this technique is shown in Fig. 1.

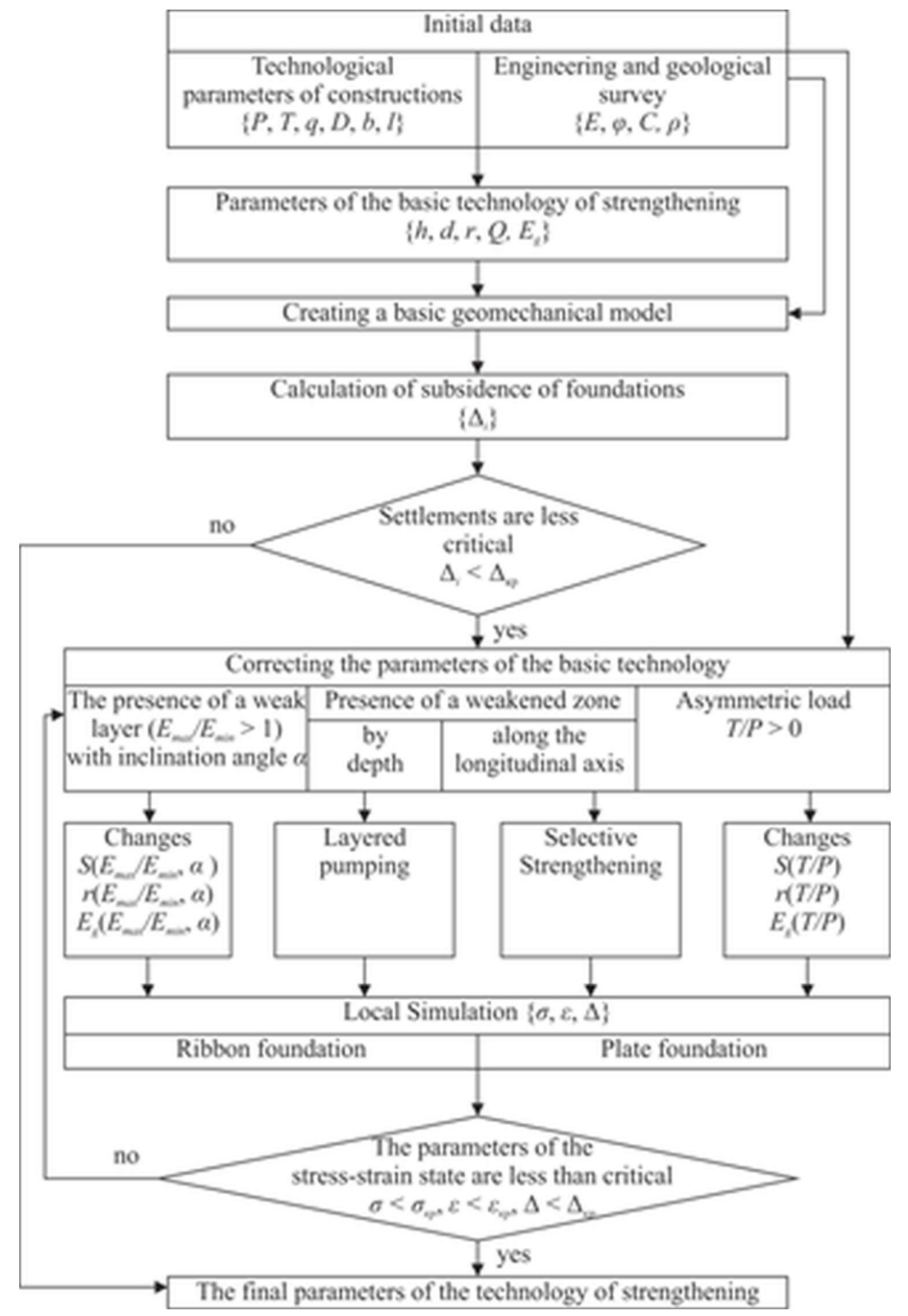

Fig. 1. Algorithm of geomechanical substantiation of technological parameters of fixing soil bases of mining-technical structures. 
The geotechnical block method is based on the division of soils into 6 types, quasihomogeneous in properties: loam and clay, unconsolidated, medium and high degree of compaction, loose soils, weathered semiccale and fractured rock. The method of geotechnical blocks includes: choice of the immersion depth of injectors $h$, solution composition and pressure, determination of the diameter $d$ of the fixing zone, including the reduction zones, hardening proper, intensive hardening, pressing and final compaction; determination of the distance between injectors $r$ in the ordinary and bush arrangement; determination of the solution consumption $Q$, calculation of the effective strain modulus $E_{g}$ and geomechanical verification of the projected geotechnological block according to standardly criteria.

The difference of the complex method consists in the detailed description of the geomechanical forecast taking into account the real heterogeneity of the soil properties. After determining the parameters $h, d, r, Q, E_{g}$ according to the basic method of geotechnical blocks, a prediction is made that the critical normative values by settling are exceeded using the basic geomechanical model. On the potentially damaged areas of the facility parameters are adjusted on the basis model, depending on operation of factors or their combination (the presence of a weak layer or a weakened zone, an asymmetric load) and produce a local geomechanical simulation for the final verification of the standard stress values $\sigma$, deformations $\varepsilon$, and settling $\Delta$.

The objects of application of recommendations on the geomechanical substantiation of parameters of unstable ground bases are buildings for production and non-production purposes, mining-technical buildings, transport, energy, dams, pipes, masts and others.

The base of L-shaped in terms of construction is complicated by various types of soil with the presence of lenses of weakened, water-saturated and subsidence soil (Fig. 2). The physical and mechanical properties obtained as a result of engineering and geological surveys for these engineering-geological elements are presented in Table. 1.

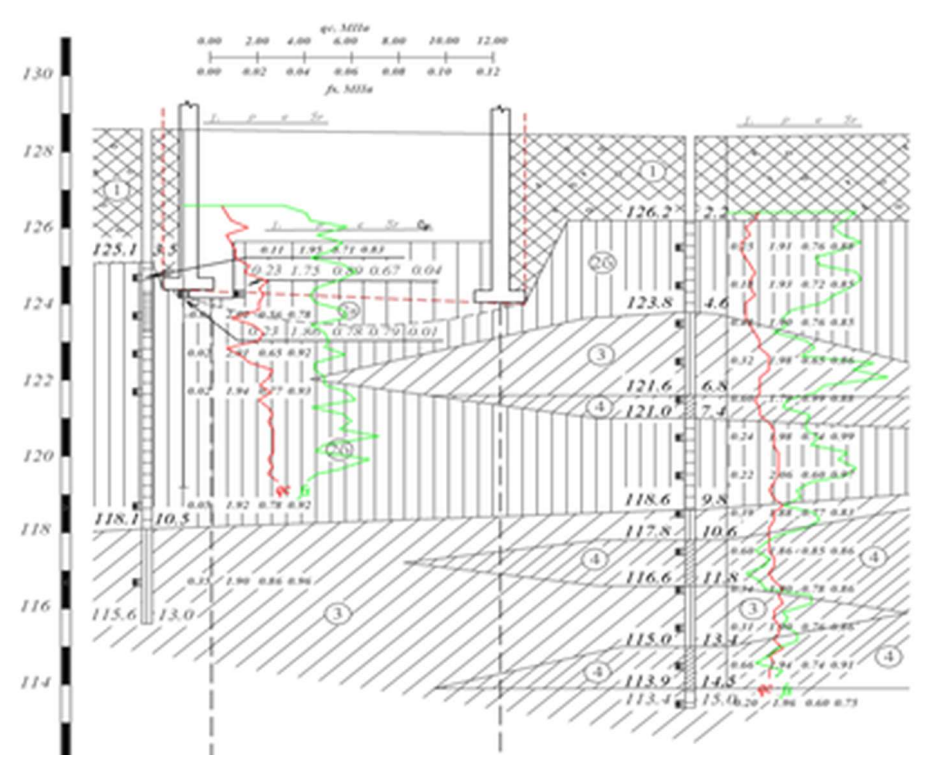

Fig. 2. Engineering-geological section at the base of the building: 1-4 - engineering-geological elements (IGE). 
Table 1. Summary table of mechanical properties of engineering-geological elements.

\begin{tabular}{|c|c|c|c|c|c|c|c|}
\hline \multirow[b]{2}{*}{ No } & \multirow{2}{*}{$\begin{array}{l}\text { Name of physical and } \\
\text { mechanical properties }\end{array}$} & \multirow[b]{2}{*}{ Units } & \multicolumn{5}{|c|}{ Number of engineering-geological elements } \\
\hline & & & IGE-1 & $\begin{array}{l}\text { IGE- } \\
2 \mathrm{a}\end{array}$ & $\begin{array}{l}\text { IGE- } \\
2 \mathrm{~b}\end{array}$ & IGE-3 & IGE-4 \\
\hline 1 & $\begin{array}{l}\text { Natural density } \rho \text { : } \\
\text { - in the natural state } \\
\text { - when wet }\end{array}$ & $\mathrm{g} / \mathrm{sm}^{3}$ & $\begin{array}{c}1.90 \\
-\end{array}$ & $\begin{array}{l}1.77 \\
1.87\end{array}$ & $\begin{array}{l}1.94 \\
1.79\end{array}$ & $\begin{array}{l}1.91 \\
1.88\end{array}$ & $\begin{array}{c}1.89 \\
-\end{array}$ \\
\hline 2 & $\begin{array}{l}\text { Angle of internal friction } \varphi \text { : } \\
\text { - in the natural state } \\
\text { - when wet }\end{array}$ & deg. & $\begin{array}{c}18 \\
-\end{array}$ & $\begin{array}{l}14 \\
10\end{array}$ & $\begin{array}{l}17 \\
12\end{array}$ & $\begin{array}{l}13 \\
12\end{array}$ & $\begin{array}{c}13 \\
-\end{array}$ \\
\hline 3 & $\begin{array}{l}\text { Clutch } C \text { : } \\
\text { - in the natural state } \\
\text { - when wet }\end{array}$ & $\mathrm{kPa}$ & $\begin{array}{c}10 \\
-\end{array}$ & $\begin{array}{l}23 \\
10\end{array}$ & $\begin{array}{l}30 \\
12\end{array}$ & $\begin{array}{l}17 \\
12\end{array}$ & $\begin{array}{c}15 \\
-\end{array}$ \\
\hline 4 & $\begin{array}{l}\text { Modulus of deformation } E \text { : } \\
\text { - in the natural state } \\
\text { - when wet }\end{array}$ & $\mathrm{MPa}$ & $\begin{array}{c}15.0 \\
-\end{array}$ & $\begin{array}{c}11.2 \\
5.6\end{array}$ & $\begin{array}{l}23.0 \\
16.7\end{array}$ & $\begin{array}{l}9.0 \\
8.1\end{array}$ & $\begin{array}{c}7.4 \\
-\end{array}$ \\
\hline
\end{tabular}

\section{Results and discussion}

The first stage of geomechanical forecasting is aimed at analyzing the calculated vertical displacements based on the basic geomechanical models in the longitudinal and transverse directions, shown in Fig. 3, and their comparison with the data of natural instrumental measurements.

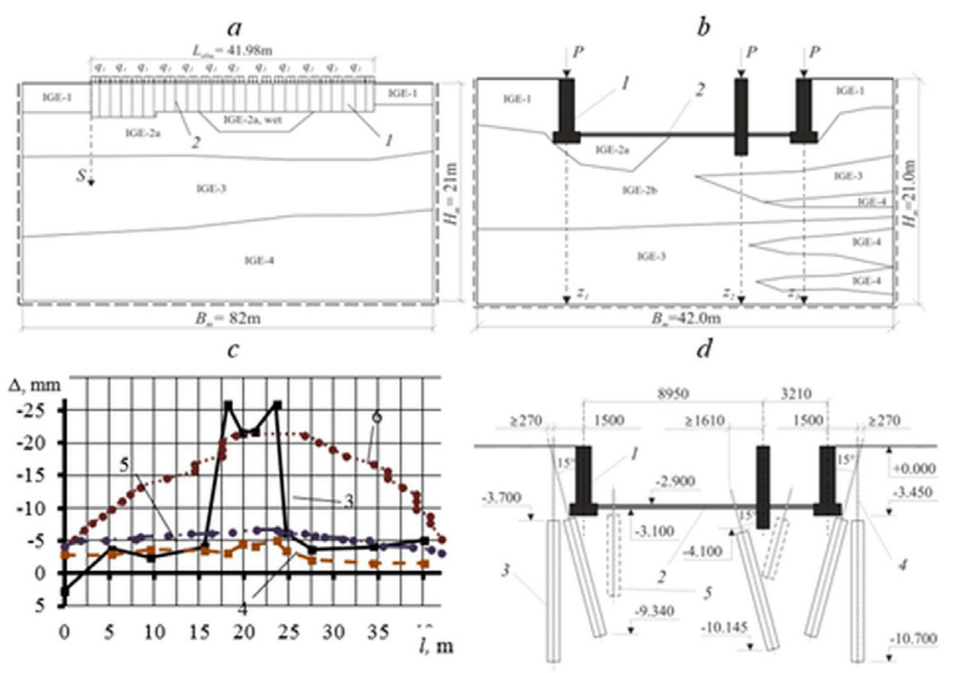

Fig. 3. Diagram of the longitudinal $(a)$ and transverse base model $(b)$, the distribution of vertical displacements $\Delta(c)$ along the western facade of the building and the fixation scheme $(d)$ : 1 foundation; 2 - modified seam-crack; 3 - actual values before fixing; 4 - actual values after fixing; 5 projected before consolidation; 6 - predicted values after fixing; 7 - basement floor; 8 - fixing zone; 9 - injector; 10 - additional fixing zones.

Analysis of the dependencies of actual observations prior to fixation showed that in the areas of technogenic accident the values of $S$ exceed the average values more than 2.5 times, and after fixing, the maxima of $S$ are smoothed out, i.e. uneven precipitation is 
eliminated. Attention is drawn to sharp changes in the graphs of $S(l)$ instrumental measurements (graph 1 in Fig. 3,c). The calculated graphs 3 are much smoother, at this the differences in the maximum values of $S$ at these boundaries do not exceed $20 \%$. The predicted values of $S$ after are holding work of fixing are comparable with the actual values and have an average deviation from real measurements of not more than $17.3 \%$.

Numerical models of artificial soil bases are based on the fixing scheme jointly developed with the engineers of LLC "Noocenter" (Fig. 3, $d$ ). The location of injectors in this scheme is taken in accordance with the basic method and takes into account a number of previously obtained recommendations for similar objects, described in $[14,15]$. The adopted fixing scheme provides a reduction in economic costs and is consistent with the technology of repair and recovery operations for these design solutions.

The picture of deformation distribution (Fig. 4) has similar outlines with stress isolines: the deformation is not asymmetric, mainly concentrated in the area of the wet soil. At the fixed of soil bases deformation $\varepsilon_{z}, \varepsilon_{x}$ are redistributed, forming the concentration areas under the right foundation (IGE-3) with preservation of deformations in the wet part.

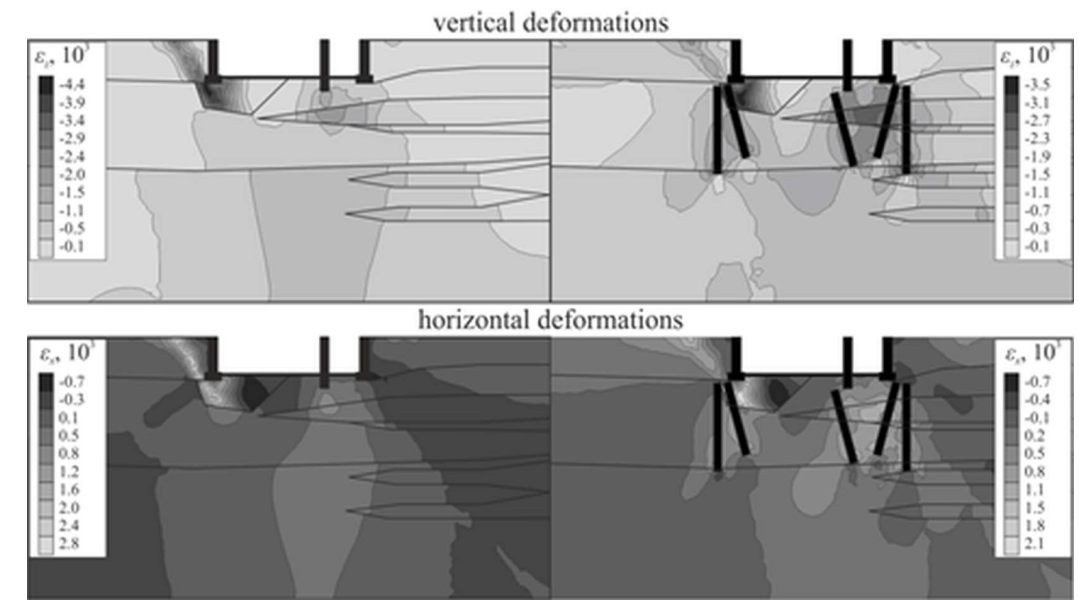

Fig. 4. The fields of isolines of vertical $\varepsilon_{z}$ and horizontal $\varepsilon_{x}$ deformations in a natural and artificial soil massif.

Particular cases of the distribution of deformations $\varepsilon_{z}, \varepsilon_{x}$ along the depth of the model along the axes $z_{1}, z_{2}, z_{3}$ are shown in Fig. 5.

The distribution of deformations $\varepsilon_{z}$ in the array occurs unevenly, with the formation of strain differences at the boundaries of the layers of the massif and the fixing zones. In the condition of a natural massif, the deformations of $\varepsilon_{z}$ have a maximum of values in the interval $z_{l}=3.45 \ldots 5.60 \mathrm{~m}$ due to significant deformations within the wet part of the soil bases, including plastic deformations based on shift criterion of the Coulomb-Mora. When you introduce in the given area of the massif the fixing zones, deformations decrease. Within the fixing zone, an increase in the deformations $\varepsilon_{z}$ as a consequence of the bending of the inclined fixing zone was observed on the interval $z_{l}=6.0 \ldots 11.5 \mathrm{~m}$. Along the $z_{2}$ axis, deformations of the inclined zone in the interval $z_{2}=6.0 \ldots 11.5 \mathrm{~m}$ are also noted, however, in the interval $z_{2}=11.5 \ldots 20.0 \mathrm{~m}$, the decline of deformation of $\varepsilon_{z}$ was noted, whereas for the artificial base the zone of influence from the middle foundation are decreases. The deformations $\varepsilon_{z}$ along the $z_{3}$ axis decrease on the interval $z_{3}=12.3 \ldots 20.0 \mathrm{~m}$ and increase significantly on the interval $z_{3}=3.5 \ldots 11.0 \mathrm{~m}$. 
$a$
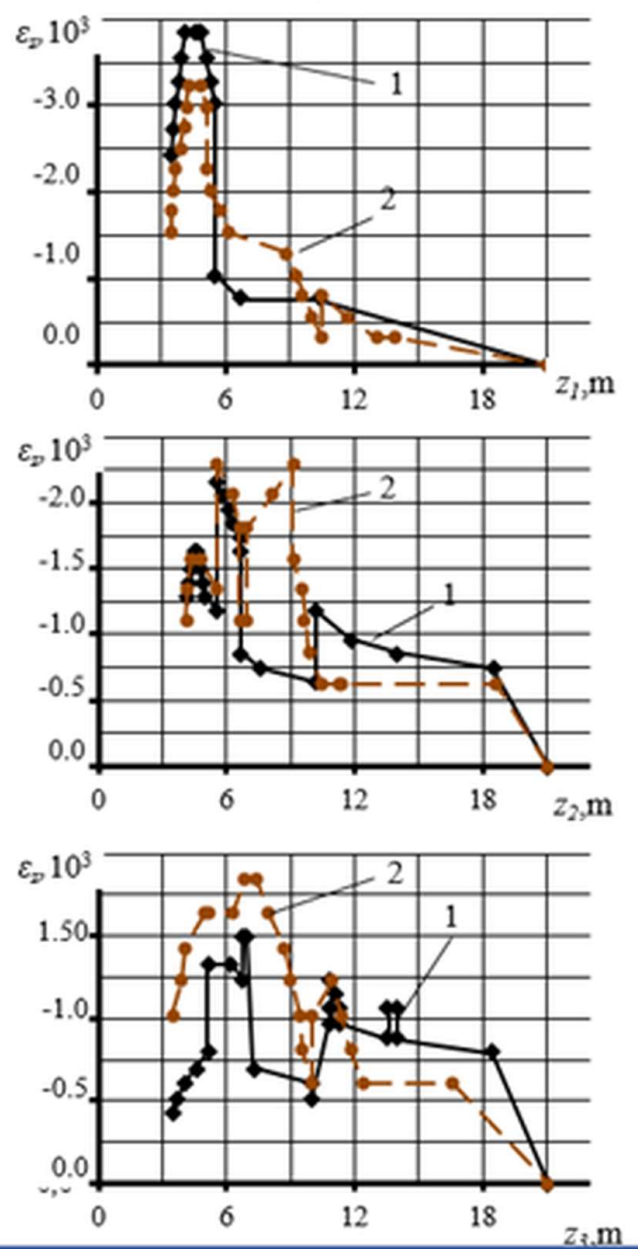

$b$
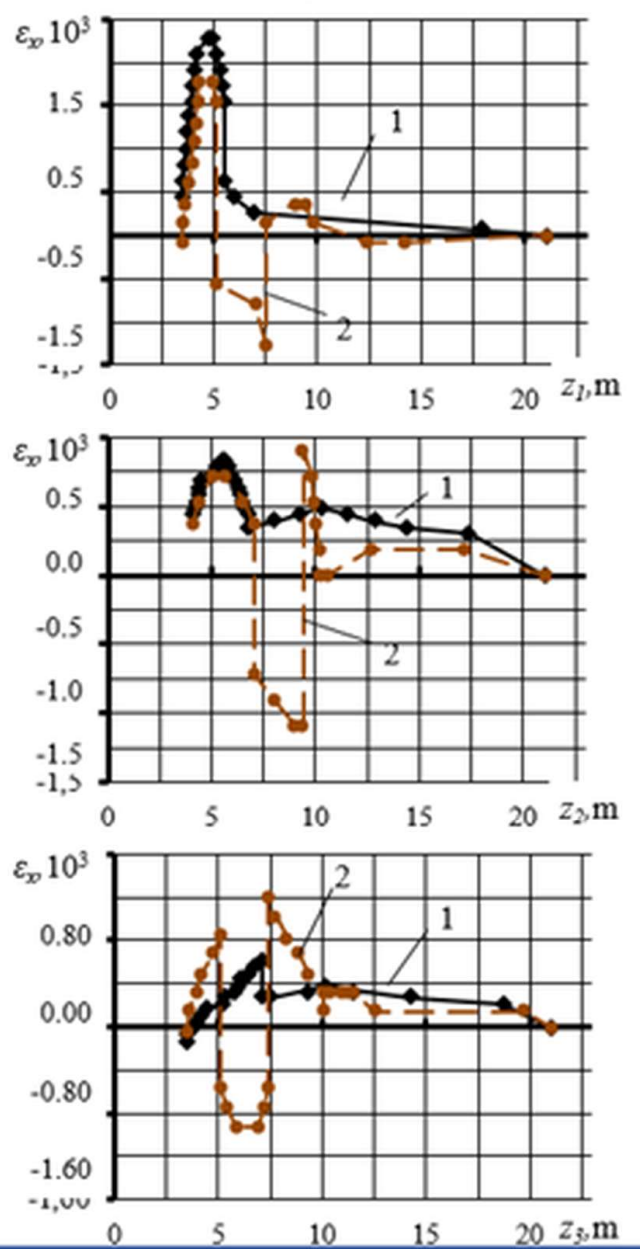

Fig. 5. Dependences of vertical $(a)$ and horizontal $(b)$ deformations on the depth of the model $z$ along the axes $z_{1}, z_{2}, z_{3}: 1$ - in the natural array; 2 - in an artificial massif.

\section{Conclusions}

1. Analysis of vertical deformations showed that the introduction into the calculation of fixing zones in some cases reduces the zone of influence of the load, while the inclined zones are subject to a greater bending effect than vertical ones. Horizontal deformations have a simpler form of distribution with a smaller difference in the magnitude of deformations at the boundaries of the layers at their concentration, mainly in the nearsurface layers. When considering an artificial massif, horizontal deformations have analogous features: the transverse deformations within the fixing zones are much higher than the deformations $\varepsilon_{x}$ of the unfixed array; along the axis $z_{l}$ deformation $\varepsilon_{x}$ in the zone of wet soil decrease with the introduction of fixing zones; along the axis $z_{3}$ there is an increase in positive deformations $\varepsilon_{x}$ before and after the fixing zone.

2. As a result of the research, the effectiveness and informative value of the geomechanical forecast of both vertical subsidence and spatial changes of the stress-strain state in individual sections of the object was confirmed. The use of the numerical prediction 
method significantly reduces the cost of mine surveying and allows early prevention of emergency situations. Based on the geomechanical data, it is possible to improve the technology and fixing schemes. In this case, it is recommended to use additional anchoring zones within the boundaries of layer of the wet soil to improve its deformation properties and prevent the development of horizontal deformations.

\section{References}

1. M. N. Ibragimov, Soil Mech. and Foun. Engin., 50, 200 (2013)

2. M. N. Ibragimov, Soil Mech. and Foun. Engin., 52, 100 (2015)

3. Shao-Chi Chien, Fu-Chen Teng, Chang-Yu Ou, Acta Geotech., 10, 813 (2015)

4. A. Flora, S. Gargano, S. Lirer, L. Mele, Geotech. and Geolog. Engin., 9, 650 (2017)

5. S. M. Prostov, N. Yu. Nikulin, J. of Mining Science, 51, 908 (2015)

6. A. V. Azarov, M. V. Kurlenya, A. V. Patutin, S. V. Serdyukov, J. of Mining Science, 51, 1063 (2015)

7. T. V. Lobanova, S. V. Moiseev, J. of Mining Science, 45, 227 (2009)

8. A. G. Protosenya, M. A. Karasev, Soil Mech. and Foun., 51, 53 (2014)

9. L. A. Strokova, Soil Mech. and Foun. Engin., 46, 117 (2009)

10. D. Mujah, K. S. Siaw, S. Tasnim, Soil Mech. and Foun. Engin., 52, 317 (2016)

11. S. G. Bezvolev, Soil Mech. and Foun. Engin., 45, 77 (2008)

12. Z. G. Ter-Martirosyan, A. S. Abdulmalek, Soil Mech. and Foun. Engin., 44, 195 (2007)

13. D. M. Shapiro, N. N. Mel'nichuk, Soil Mech. and Foun. Engin., 44, 62 (2007)

14. S. M. Prostov, M. V. Sokolov, Taishan Acad. Forum - Project on Mine Dis. Pre-v. and Control, 350 (2014)

15. S. M. Prostov, M. V. Sokolov A. V. Pokatilov, Inter. J. of Applied Engin. Res,. 10, 45297 (2015) 